\title{
A ordem e as forças profundas na Escola Inglesa de Relações Internacionais - em busca de uma possível francofonia
}

\author{
The order and the Deep Forces in the English School of \\ International Relations - In the search of some francophonie
}

CARLOS HENRIQUE CANESIN*

Rev. Bras. Polít. Int. 51 (1): 123-136 [2008]

\section{Introdução}

Este trabalho clama por um debate metodológico que revisite a Escola Inglesa de Relações Internacionais, eminentemente uma escola de cunho histórico, com ênfase para a adoção de tal característica como seu locus stand no cenário interpretativo da disciplina de Relações Internacionais.

O debate em torno da Escola Inglesa tem sido animado especialmente por um viés bastante crítico em relação à pretensa falta de coerência metodológica desta corrente interpretativa e tem mesmo ecoado certa dose de preconceito pela argumentação fortemente behaviorista de que a constante autovinculação da escola aos autores clássicos do campo e a preferência pelos métodos mais difusos destes a tornariam um empreendimento pouco promissor.

Isto seria conseqüência de uma mutação no próprio conceito de ciência gestado durante o decorrer do século XIX nas áreas de ciências exatas e que chega ao campo das ciências humanas e sociais no século XX, desenvolvendo-se com maior rapidez aproximadamente no pós Segunda Guerra Mundial. Tal mudança acabou por gerar um ambiente acadêmico onde as ciências humanas e sociais compartimentam-se em busca de uma formalização crescente de seus corpos teóricos e maior replicabilidade de seus estudos, imitando e adaptando métodos quantitativos utilizados nas ciências exatas - com ampla utilização de métodos estatísticos.

A discussão em torno da coerência metodológica da Escola Inglesa tem assim, em grande medida, se dado sobre as mesmas bases das críticas dirigidas às ciências humanas e sociais em geral e às quais estas têm tentado responder com maior ou menor sucesso durante todo o século XX e que se perpetuam mesmo após o movimento pós-modernista e o início do presente século XXI.

* Mestrando em Relações Internacionais pela Universidade de Brasília - UnB (canesin@unb.br). 
No tocante à disciplina de Relações Internacionais, sobretudo em seus desenvolvimentos conectados à Ciência Política, este esforço pode ser observado pela incorporação de métodos quantitativos derivados da economia, como no caso da teoria dos jogos, e por formulaçôes teóricas elegantes como o estruturalismo.

É em contraste principalmente com estes desenvolvimentos que Roy Jones (1981) chega a afirmar em seu famoso artigo "The English School of International Relations: A case for closure" que a Escola Inglesa não seria mais do que um pequeno clube de autoproclamados pertencentes à tradição que, no entanto, não partilhariam necessariamente bases ontológicas comuns. Dessa forma, chega Jones a afirmar que a contribuição desta escola à literatura na área seria cada vez mais estéril - chegando a recomendar o abandono de suas linhas de pesquisa na London School of Economics (LSE), apontada pelo autor como o principal centro de convergência dos estudiosos desta linha.

Estas críticas têm sido estendidas e periodicamente veiculadas em publicaçôes da área. Chegando recentemente Ian Hall (2001), em um artigo intitulado de "Still the English patient? Closures and Inventions in the English School", a criticar abertamente a própria historicidade presente nos trabalhos de vários autores vinculados à tradição.

O que a grande maioria das críticas, sobremaneira as dirigidas por parte de pesquisadores norte-americanos, à Escola Inglesa têm em comum, no entanto, é um constante erro de foco. A discussão tem sido travada em torno da oposição entre a vinculação buscada pela tradição inglesa a um tipo de produção científica mais clássica e menos compartimentada face à nova concepção ideal e absolutamente normativa de ciência pós-baconiana, que encontrou abrigo em meio à disciplina de Relações Internacionais do outro lado do atlântico.

O debate e a crítica são fundamentais ao amadurecimento de idéias e desenvolvimento científico lato senso e, portanto, louváveis quando corretamente empregados. $\mathrm{O}$ debate travado a partir de encastelamentos doutrinários, com base em uma normatividade científica, são, no entanto, infrutíferos.

Dessa forma, neste artigo se pretende inquerir por um debate em torno da Escola Inglesa com foco objetivo no que a mesma constitui, e finalidades às quais se autodetermina, e não em torno de um dever ser orientado pela opinião de expoentes vinculados a outras correntes interpretativas.

A Escola Inglesa de Relações Internacionais é uma escola de base histórica e deve, assim, ser discutida em termos de sua historicidade. Seus métodos, para determinar sua aplicabilidade e efetividade, devem ser comparados e avaliados com vistas a outros métodos que partilham da mesma finalidade - um desenvolvimento em perspectiva histórica da disciplina.

Neste sentido, as críticas ontológicas, para uma verdadeira efetividade e mesmo contribuírem para o desenvolvimento da tradição inglesa, devem provir de disciplinas e escolas históricas. É necessário, no entanto, o prévio estabelecimento das bases comparativas para tal empreitada. 
Esta constatação é o que torna extremamente útil o objetivo deste trabalho. A saber, o estabelecimento de um mecanismo de interpretação de uma das dimensões mais fundamentais das teorizaçôes da Escola Inglesa, o lugar e as tendências da ordem, por meio do arcabouço metodológico desenvolvido por uma consolidada e respeitada escola da Historiografia das Relações Internacionais, a tradição francesa, que tem bases sobretudo nos trabalhos de Pierre Renouvin e Jean-Baptiste Duroselle (1967; 1994; 2002).

Por trás da clara distinção observada na historiografia inglesa de relações internacionais entre os conceitos de "sistema internacional" e "sociedade internacional", alicerçando tais conceitos tão caros a esta interpretação histórica particular, está o conceito de ordem.

Seja ela imediata e hierárquica como nos sistemas imperiais ou mesmo anárquica, sem um centro específico de poder, como no sistema europeu emergente pós-westfália, a ordem é uma característica necessária aos sistemas internacionais históricos.

Por trás de uma atitude quase teleológica em favor da tendência ao ordenamento, que emana da construção e expansão da sociedade internacional no tempo desde a obra seminal de Hedley Bull em 1977 (A sociedade anárquica [2002]), passando pelo esforço de Adam Watsom na década de 1980 (A evolução da sociedade internacional [1992]), e culminando com as críticas e repaginamento dos anos 90 com Barry Buzan, Richard Little e Charles Jones (The logic of anarchy [1993]) e Buzan e Little (International Systems in World History [2000]) - existiriam forças profundas tal qual definidas pela tradição francesa, materiais e psicosociais, operando tais desdobramentos?

Com base na metodologia da historiografia francesa, com ênfase para as obras de Jean-Baptiste Duroselle (Todo império perecerá [2002]), de Pierre Renouvin (Histoire des Relations Internationales [1994] - com ênfase para o capítulo preparado por René Girault), e de Duroselle e Renouvin (Introdução à História das Relaçôes Internacionais [1967]), o trabalho procurará observar se sob a pluralidade característica da escola inglesa pode ser detectado um sistema de causalidades múltiplas que operariam em nível sistêmico - propiciando bases de comparação entre a interpretação desta escola e a interpretação da escola francesa.

\section{A distinção fundamental entre Sistema e Sociedade}

Antes de adentrar no tema deste trabalho propriamente dito, é frutífero que se definam os termos utilizados na escola inglesa a que se fará referência no decorrer do artigo, uma vez que a própria definição dos mesmos traz consigo os fundamentos da escola que serão revisitados sob novo olhar metodológico.

Dessa forma, iniciaremos pelas definições de sistema internacional e sociedade internacional, sendo o 'internacional' intercambiável por 'de estados' neste contexto; passaremos rapidamente pela constituição pluralista da escola que 
se funda na própria visão destes termos; para apenas a partir daí discutir o lugar da ordem nesta tradição e; em seguida lançar uma visão quanto à metodologia da escola francesa.

Por sistema internacional, tal qual definido na obra prima de Martin Wight "A Política do Poder" (2002) e repetido no trabalho de Hedley Bull "A Sociedade Anáquica" (2002), entende-se um ambiente constituído pela interação entre unidades soberanas, os estados, que se reconhecem como tal. A definição de sociedade internacional, também abordada em ambas as obras, leva em consideração os aspectos cooperativos da interação entre estados e constiui-se em um conjunto de estados, que embora soberanos, partilham certos valores e concordaram em submeter suas ações a um conjunto de regras e normas de interação, formando assim uma comunidade.

\section{A Pluralidade da Escola Inglesa}

A exemplo da própria disciplina de Relações Internacionais, que se fundou menos na oposição entre os pensamentos idealista e realista e em função desta dicotomia - em ambos os lados do Atlântico o fenômeno pode ser traçado, seja a partir da seminal obra "Vinte Anos de Crise" de Edward Carr (2001), apontado como o precursor da tradição por Tim Dunne (1989), seja a partir da fundamentação do realismo clássico feita em "A Política entre as Nações" de Hans Morgenthau (2002).

A Escola Inglesa se fundamenta em função do relacionamento e oposição de três tradições de pensamento: o realismo, o racionalismo, e o revolucionismo. Influenciado pelo pensamento dicotômico do outsider Carr, Martin Wight, que juntamente com Hebert Butterfield é apontado como um dos pais da escola (DUNNE, 1989), elabora em seu "A Política do Poder" (2002) o argumento de que o pensamento sobre o campo das relações internacionais tem historicamente se manifestado de forma vinculada a uma destas três tradições.

A primeira tradição se fundaria em Tucídides e, sobretudo, Maquiavel, sendo constituída por um sistema internacional de estados orientado segundo uma lógica de cálculo estratégico onde imperam as relações de poder e o mecanismo de interação internacional é o balanço de poder.

No caso da segunda, prevaleceria uma orientação grociana, fundada em uma sociedade internacional de estados, com forte influência também de Pufendorf, onde as relações entre estados seriam guiadas por um senso de partilha de certos valores e pelo respeito ao direito internacional estabelecido sobre estes pilares compartilhados.

Por fim, a tradição revolucionista de uma sociedade mundial integrada não por estados, como no caso das duas anteriores, mas sim por indivíduos pertencentes a uma grande comunidade teria bases na civitas maxima do pensamento kantiano. 
Com o passar do tempo a Escola Inglesa foi-se concentrando em uma produção de literatura mais vinculada à corrente racionalista do que às demais. E embora Tim Dunne (1989) empreenda considerável esforço para classificar alguns autores como Bull na tradição revolucionista e redefinir a teoria internacional em bases normativas, esta é uma posição bastante controversa.

O pluralismo, no entanto, se mantém vivo e animado, sobretudo, pelo debate iniciado na década de 1990 entre o que Barry Buzan denominou em seu "From International System to International Society" (1993) de correntes pluralista e solidarista - cujos expoentes seriam, no primeiro caso, Robert Jackson e, no segundo, Nicolas Weelar. A primeira corrente estaria localizada no contato entre as tradições realista e racionalista e a segunda seria o extremo racionalismo em contato com a tradição revolucionista.

É a partir desta concepção interativa que Barry Buzan e Richard Little, cuja vinculação poderia ser definida como mais pluralista, respondem ao ácido artigo de Ian Hall (2001) citado anteriormente, com seu "The 'English patient' strikes back" (2001), argumentando que é o caráter histórico da disciplina que lhes permite uma passagem tão fluente entre as correntes pertencentes a estas tradiçóes e que a Escola Inglesa seria um diálogo entre as mesmas.

\section{O conceito de ordem na Escola Inglesa}

A ordem, de forma geral, tem nesta tradição uma concepção bastante particular, chegando a ser mesmo normativa. Por ordem, lato senso, entendese um determinado arranjo, segundo algum critério específico, de unidades particulares de certo tipo. Não é, no entanto, qualquer arranjo, e, portanto, qualquer tipo de ordem, em que está interessada a Escola Inglesa.

A ordem é adotada enquanto sua concepção finalística agostiniana por esta escola. Ordem é uma organização com vistas a atingir um objetivo específico. Dessa forma, segundo Bull (2002) a ordem internacional, ou ordem de estados, é um arranjo particular cujo padrão visa promover uma disposição das atividades internacionais de forma a que favoreça os objetivos primários de uma sociedade internacional composta por estes mesmos estados.

Os objetivos fundamentais de tal sociedade seriam, primeiramente, a preservação do próprio sistema de estados que garante a sobrevivência de todos e de cada um de seus membros em particular; depois, a manutenção da soberania externa de cada Estado-membro, pois, esta assegura o funcionamento do próprio sistema em si; passariam pela manutenção da paz, não tanto pelo seu valor normativo, mas em função de suas características de estabilização sistêmica e redução do risco; e culminariam na criação de regras e normas que regulassem o funcionamento desta sociedade de estados de forma a limitar o escopo para a utilização da violência dentro do sistema. 
Mais recentemente, a ordem emerge dentro esta tradição, alternativamente, descaracterizada de seu conteúdo normativo, mantendo, porém, seu conteúdo finalístico e instrumental. Sob a reformulação de Buzan, Little, e Charles Jones em The logic of Anarchy (1993), a ordem é vista como potencialmente um fruto possível da interrelação de estados auto-interessados com agenda voltada para assuntos de segurança, dentro de um modelo neo-estruturalista.

Esta formulação vê a ordem como resultado de uma "capacidade de interação" dos estados, a partir de um comportamento derivado de uma lógica adaptativa da anarquia diferente da lógica usual de anarquia do pensamento do realismoestruturalismo waltiziano (WALTZ, 1979). O que implica que a ordem pode ser atingida não apenas por meio do estabelecimento de uma sociedade de estados que partilhem certos valores e que promovam um arranjo para a perpetuação de um sistema que garanta tais valores, mas também em um ambiente de self-help na ausência de qualquer compartilhamento de valores, uma vez que da própria lógica da anarquia poderia emergir uma sociedade internacional que estabelecesse determinadas regras de conduta com interesse exclusivamente na perpetuação das suas unidades componentes.

\section{O lugar da ordem na Escola Inglesa}

A ordem emerge desta tradição, quer seja em sua concepção normativa defendida por Bull (2002), quer em seu repaginamento neo-estruturalista de Buzan e Little (1993), como uma tendência do sistema internacional. Um conjunto de estados soberanos em interação tenderia, quer racionalmente quer axiologicamente, a preferir um sistema fundado em um ordenamento finalístico que promova ao menos o objetivo de perpetuação do próprio sistema.

A ordem tal qual estabelecida pela Escola Inglesa resolve o clássico problema hobbesiano do estado de natureza que caracterizaria o cenário internacional, que carece de um poder hegemônico como no nível doméstico. Devemos à esta tradição, e mais especificamente a Bull cujo subtítulo de sua principal obra é "Um estudo da ordem na Política Mundial" (A Sociedade Anárquica, 2002), a didática diferenciação, tantas vezes repetida posteriormente pelos teóricos do campo, entre caos e anarquia.

Sendo o caos um estado de ausência de ordem por sua própria definição e a anarquia caracterizada apenas pela ausência de uma autoridade hegemônica que vincularia todas a unidades pertencentes a um determinado sistema, a anarquia não pressupõe a existência de caos. A anarquia pode se conciliar com a ordem através do compartilhamento de valores que edificam uma sociedade internacional imbuída de objetivos específicos, e, portanto, ordenada - deriva daí o nome da obra de Bull.

Adam Watson em seu A Evolução da Sociedade Internacional (1992), que analisa de forma comparada os sistemas históricos de estados, e, portanto, a materialização 
própria da ordem no cenário internacional em suas particularidades históricas, não constrói uma concepção diversa do termo da que tem Bull.

Watson (1992), com a sua explanação quase teleológica acerca do pêndulo que movimentaria a histórica de forma cíclica entre dois arranjos sistêmicos extremos, apenas enfatiza que por "ordem" entende um padrão de relacionamento cuja finalidade principal é a manutenção da paz. Assim, a paz é uma característica definidora da ordem - que é sempre restrita ou pelas açôes de uma comunidade internacional estabelecida, ou de forma autocrática, e até opressiva, pelos governantes, a depender em que fase do pêndulo se encontre o sistema.

A comunidade internacional estaria presente na fase extrema do pêndulo denominada de "independências múltiplas", onde a ordem é flexibilizada em favor de regras de conduta auto-impostas, em que o sistema é composto por uma determinada quantidade de estados independentes e soberanos cujas relaçôes são horizontais, voluntárias, e que culminam na formação de alianças, pois, não podem operar sozinhos no sistema internacional.

No campo oposto, o extremo do pêndulo onde a ordem é mais estável fundase no uso da coerção por parte de um estado mais forte para subjugar estados mais fracos e trazê-los para dentro de seu aparato administrativo doméstico, eliminando o ambiente internacional. Este estágio é denominado de "domínio" e é caracterizado pela prevalência dos impérios e pelas relações verticais de suserania. Seja qual for a fase do pêndulo, a ordem é mais do que uma meta passível de realização, é sempre uma tendência dos sistemas - variando apenas seu grau de efetividade e vinculação.

Buzan e Little, continuando a pesquisa iniciada em "The logic of anarchy" (1993) juntamente com Jones, publicam em 2000 "International Systems in World History" no qual, retomando a diversidade de lógicas que emanam da anarquia, avançam o programa de Watson de estudo comparado dos sistemas de estados na história, através de sua metodologia mais neo-estruturalista, realizando uma viagem por 60.000 anos de história humana.

Neste estudo, os autores empreendem uma ampla categorização dos tipos de sistemas de estados na história, que embora não nos interessem diretamente aqui, levaram os autores a conclusóes importantes para o desenvolvimento deste trabalho. Buzan e Little rejeitam cabalmente os pressupostos do realismo estrutural de Waltz ao afirmarem que as mudanças no sistema internacional são sempre estruturais e não provém das unidades.

Os autores não utilizam meias palavras também para mencionar o que Watson deixa apenas antever de forma implícita, o sistema internacional mais funcional é sempre o hierárquico e não o anárquico. Por funcional, claro, entendese a concepção finalística de um sistema - a ordem. As fontes de explicação para os desdobramentos internacionais, e para o ordenamento, passam, dessa forma, pela própria inter-relação entre os estados, no que descreveram previamente em "The logic of anarchy" como "capacidade de interação", pelo processo mesmo de relacionamento, e pela estrutura do sistema. 


\section{A tradição francesa}

A Escola Francesa de Relaçóes Internacionais, ao contrário de sua contraparte do outro lado do Canal da Mancha, não enfrentou maiores obstáculos para a sua consolidação e institucionalização. Isto se deveu em parte à força das disciplinas históricas no seio da comunidade acadêmica francesa, em parte ao rápido florescimento de uma arquitetura interpretativa própria da corrente historiográfica dedicada às relações internacionais neste país.

A tradição francesa com muita propriedade avançou a pesquisa histórica na disciplina para muito além dos limites da história diplomática praticada até então, desenvolvendo uma nova ontologia histórica de dimensão eminentemente societária aplicável à vida internacional.

A consolidação desta tradição através do que Pierre Renouvin e Jean-Baptiste Duroselle estabelecem como objetivo em "Introdução à História das Relaçôes Internacionais" (1967), a procura por identificar regularidades e extrair dos dados disponíveis, oriundos de pesquisa empírica, as conclusóes teóricas ao invés de inserir os dados coletados em modelos conceituais analíticos prévios, aproxima esta tradição do modelo de trabalho estabelecido por Martin Wight em sua busca de regularidades e padrões de pensamento em relaçóes internacionais.

Esta postura torna a Escola Francesa também bastante desconfiada, a exemplo da tradição inglesa, dos modelos estáticos de análise dos fenômenos internacionais; da elegância e pretensa segurança de explicaçōes universalistas; e do que Duroselle chama de "fetiche do matematismo" em seu "Todo Império Perecerá" (publicado no Brasil em 2000).

Neste sentido, a aproximação entre as escolas salta imediatamente aos olhos e parece nos fornecer uma base para interoperabilidade entre os anseios das mesmas. Nos cabe, então, avançar a especulação sobre se estas atitudes e estes posicionamentos similares face ao fenômeno internacional se refletirão em uma possibilidade de interoperabilidade entre os conceitos destas mesmas escolas.

A saber, mais especificamente a factibilidade do objetivo deste trabalho, a análise da concepção inglesa de ordem e seu lugar nos sistemas históricos de estados, nos moldes do arcabouço interpretativo desenvolvido pela tradição francesa. Para tanto, empreenderei uma breve discussão da metodologia francesa e dos componentes de seus sistemas de causalidade e finalidade, para a partir daí revisitar o lugar da ordem no sistema internacional utilizando um discursso à la française.

\section{Metodologia francesa}

A tradição francesa, ao rejeitar as explicações universalistas, desenvolveu o conceito de "multicausalidade" (Duroselle, Renouvion, 1967; Duroselle, 2000), que diferentemente do significado de causalidade observado na ciência política após a revolução behaviorista anteriormente aludida, implica na constituição de 
um vetor aberto de causas, ou influências, que não exaurem necessariamente as explicações para desencadeamento de determinado fenômeno - atuando sempre como influências com pesos variados em cada situação específica.

Esta multicausalidade sempre condicional e específica a cada situação, carecendo, portanto, de análise empírica sempre que se procura determinar um vetor de causas, decorre da ausência de uma teoria programática das relaçóes internacionais nesta escola. Teoria, enquanto conteúdo produto da reflexão orientada, se confunde com a própria metodologia da escola.

A explicação é sempre particular de um determinado fenômeno, desenvolvida através do emprego de um arcabouço de variáveis definidas como potencialmente explicativas dos fenômenos internacionais. A validade de cada variável é, no entanto, contingente a cada fenômeno específico - o que gera um vetor de causalidade em cada situação particular, mas que no avolumar-se dos estudos do continuum histórico pode fazer vislumbrar regularidades e padrões dos acontecimentos. Fomentando assim, a construção de uma teoria baseada na história e não o contrário, uma interpretação da história com determinada perspectiva teórica.

A tradição francesa concebe estas variáveis potencialmente componentes deste vetor de causalidade como pertencentes a um "sistema de causalidade" (Duroselle, Renouvion, 1967; Duroselle, 2000). Por seu conteúdo histórico, cada uma destas variáveis é chamada de uma "Força Profunda", atuando como um bruit du fonde continuamente no tempo histórico. O sistema de causalidade é composto, portanto, das forças profundas.

Estas forças profundas atuariam sobre a ação do estado, constrangendo-lhes e limitando-lhes dentro de determinadas direções. Mais propriamente, Duroselle e Renouvin afirmam que estas forças atuam sobre o que chamam de "homem de estado" (Id. Ibid). O "homem de estado" é um tipo ideal, caracterizado por um determinado temperamento e peculiaridades, que tem por atribuição definir os objetivos a serem atingidos por determinado estado - utilizando-se para tanto de determinados mecanismos de decisão.

Para nosso objetivo específico neste trabalho, não consideraremos a unidade decisória do modelo francês exposto. Para nós, no momento, não interessa a constituição interna do estado e as características de seu governante. A decisão pode ser fruto de uma inteligência humana ou produto de um output automático de um estado monolítico, isto não influenciará a análise.

Cabe apenas mencionar que estes objetivos específicos, independentemente da forma como forem definidos, consistem em um vetor de objetivos ou "sistema de finalidade" (Id. Ibid), que nada mais é do que a representação racional de objetivos estabelecidos de forma transitiva.

O sistema de finalidade é composto de duas dimensões, uma que se refere ao processo de cálculo estratégico, englobando todas as suas variáveis desde a definição de fins/objetivos, a avaliação de riscos e a definição dos meios para atingir os fins estabelecidos; e uma referente à política externa, que se 
refere à ação prática do homem de estado, sendo definida por suas diretrizes particulares.

\section{As forças profundas}

As "forças profundas" atuam sobre os componentes das relações internacionais, os homens de estado, doravante considerados como estados monolíticos. Estes estados possuem determinados objetivos presentes em seu sistema de finalidades, objetivos os quais não nos importa o mecanismo pelo qual foram estabelecidos. Esta interação entre os estados, o sistema de causalidade e o sistema de finalidade, produz os movimentos da vida internacional - caracterizado por suas ondas criativas; por relações pacíficas ou conflituosas, e, finalmente, pela guerra (DUROSELLE, 2000).

Estas "forças profundas" são de diversos tipos e Renouvin as enumera na primeira parte da obra "Introdução à História das Relaçôes Internacionais" (1967) como: geográficas; demográficas; econômicas; da mentalidade coletiva; e correntes sentimentais. Sendo a primeira composta por atributos de posição e espaço que orientam a alocação dos agregados humanos. No segundo caso, discorre-se sobre o papel dos surtos demográficos e movimentos migratórios como constrangimentos do ambiente internacional.

Quanto às forças econômicas, estas são divididas entre materiais e financeiras e entre conflitivivas e cooperativas. No tocante à mentalidade coletiva, destaca-se o papel constitutivo de sentimento nacional. E, finalmente, dentre as correntes sentimentais Renouvin dá ênfase aos movimentos nacionalistas e aos pacifistas. A única característica comum a todas as forças é o seu caráter perene enquanto causa histórica potencial do desencadeamento de fenômenos e sua regularidade observável no tempo.

\section{Em busca de uma francofonia}

Como pode ser vocalizado o fundamental conceito de ordem presente, e digo mesmo onipresente, na Escola Inglesa, seja em sua vertente mais clássica e agostiniana tal qual a define Bull (2002), seja em seu repaginamento pluralista neo-estruturalista (BUZAN, JONES, LITTLE, 1993; BUZAN, LITTLE, 2000), segundo a tradição interpretativa francesa? Qual seria o lugar da ordem neste sistema dual da metodologia historiográfica francófona?

Para fornecer uma resposta a ambas as questôes a que nos colocamos, afirmo que temos de partir da íntima relação que estas perguntas possuem sob a perspectiva inglesa. Sob esta perspectiva interpretativa, diferentemente da compartimentação entre causalidade e finalidade observada no pensamento francês metodologicamente mais rigoroso, o que coloca os componentes de cada um destes sistemas e lugares específicos do modelo, o próprio conceito 
de ordem tal qual estabelecido na Escola Inglesa evoca ambas as dimensōes de causa e fim.

Dessa forma a simples definição de ordem sob os auspícios do modelo francês, mantida a carga de significância atribuída ao termo pela Escola Inglesa, implica automaticamente na determinação de seu lugar específico no modelo.

$\mathrm{O}$ que caracteriza o conceito de ordem em qualquer de suas formulaçōes por sob as diretrizes da tradição inglesa, é o seu conteúdo finalístico. A ordem é uma organização com vistas a um conjunto de objetivos específicos. O principal objetivo é a manutenção sistema internacional, garantindo, assim, a sobrevivência de suas partes constituintes, sendo este o único objetivo factível na concepção de Buzan e Little.

No entanto, a estrutura específica para a promoção deste objetivo de perpetuação do sistema internacional é a própria ordem, em sua conformação particular em cada período histórico representado pelo sistema de estados histórico que lhe for contemporâneo. O que implica que a ordem, enquanto um arranjo determinado, passa a ser o próprio objetivo primordial de uma sociedade de estados. É neste sentido que tenho afirmado anteriormente que a ordem é eminentemente um atributo teleológico enquanto tendência na Escola Inglesa.

Apresentada a crítica de maneira bastante intuitiva, vejamos como podemos superá-la por meio da metodologia da historiografia francesa. Empreendamos uma separação artificial e meramente didática da ordem enquanto fim e da ordem enquanto meio no seio da Escola Inglesa. Se pensarmos na ordem enquanto fim e interpretarmos a sua busca e consecução como uma decisão consciente do estado, ou do homem de estado, a ordem como arranjo específico estaria claramente dentro do sistema de finalidade do modelo francês.

O fim último é a sobrevivência do próprio estado enquanto tal, o que coloca em plena sintonia a transitividade axiológica atribuída aos estados, ou aos homens de estado, tanto na formulação inglesa quanto na formulação francesa. E a sobrevivência do estado se faz, como afirmado anteriormente, através da preservação do sistema internacional, que representa em cada tempo um ordenamento específico. A ordem-fim é, dessa forma, produto do cálculo estratégico do estado, ou do homem de estado. Interpretação esta que se assemelharia bastante com as elaboraçōes de Buzan e Little apresentadas anteriormente ao tratarem das diversas lógicas da anarquia, sem, no entanto, ferir os pressupostos das formulações mais clássicas da Escola Inglesa.

Se pensarmos na ordem enquanto meio para a consecução desta finalidade específica de garantir a sobrevivência do estado, ou seja, na ordem-meio como uma política específica ativamente buscada pelo estado, ou homem de estado, devido a seus valores particulares, podemos concebê-la como a diretriz de política exterior escolhida por este componente do sistema. 


\section{Conclusão}

Estas elaborações não traem o espírito da ordem na Escola Inglesa e têm a vantagem de solucionar o recorrente problema teleológico do lugar da ordem enquanto tendência nesta tradição. Sob esta arquitetura, é possível manter a ordemfim como característica de uma sociedade de estados, que compartilhem valores além da simples manutenção dos mesmos enquanto unidades de um sistema de múltiplas independências; ao mesmo tempo em que se concilia a ordem-fim com o espectro de domínio do pêndulo de Watson (1992), tendendo ao império e às relações suseranas onde a ordem é sinônimo de paz.

Ao mesmo tempo preserva-se a ordem-meio como uma diretiva determinada de política externa que não mais se confunde com seu fim. Podendo a ordemmeio constitui-se quer no estabelecimento e respeito a regras e normas de uma sociedade internacional na primeira fase do pêndulo, quer no estabelecimento de domínio das demais unidades na fase de império.

A vantagem desta formulação é que a Escola Inglesa escapa assim também de outras críticas advindas do campo da história acerca de sua predileção pelo discurso político como explicação. A francofonia inglesa permite que se expanda a agenda de investigação da tradição inglesa de maneira bem estruturada, utilizando a agenda investigativa do sistema de causalidade para teste das forças profundas atuando em favor e contra a ordem-fim em cada um dos sistemas de estado histórico, que constituem-se um arranjo ordenado particular e, portanto, são manifestaçōes históricas das apresentaçōes da ordem-meio.

O desenvolvimento de linhas de pesquisa que incorporem este diálogo entre a Escola Inglesa e a tradição francesa continental, empreendendo estudos, de forma comparada entre os sistemas históricos de estados, dos efeitos da ampla gama de forças profundas sobre a ordem-fim, ajudaria a Escola Inglesa a entender melhor e de forma mais sistemática a constelação de fenômenos que contribuem para o ordenamento.

Os estados, ou homens de estado, a depender da definição da unidade de análise, em interação uns com os outros em um ambiente internacional constrangido por um sistema de causalidade do tipo das forças profundas, produziriam em sua interrelação, na qual todos buscam a consecução de ao menos um objetivo comum, a ordem-fim estabelecida no sistema de finalidade, os movimentos e as ondas da história.

Estes movimentos se materializariam, em cada momento histórico particular constrangido por seu próprio vetor de forças profundas, em três tipos de relações entre estados - pacíficas; conflituosas; ou bélicas, esta representando a falha última na consecução da ordem. A lógica nos sugere que poderíamos encontrar os sistemas históricos de estados entre as duas primeiras relações, com a primeira prevalecendo no caso de independências múltiplas e a segunda no espectro imperial de dominação coercitiva. Cabe, no entanto, à pesquisa empírica 
determinar os sistemas de causalidade operando em favor de cada um destes arranjos específicos da ordem.

Recebido em 9 de outubro de 2007

Aprovado em 30 de abril de 2008

\section{Referências bibliográficas}

BULL, Hedley. (2002), A Sociedade Anárquica. Brasília, IPRI - Ed. UnB.

BUZAN, Barry. (1993), "From International System to International Society: Structural realism and Regime Theory meet the English School”. International Organization, v. 47, n. 3, p. 327-352.

BUZAN, Barry; JONES, Charles; LITTLE, Richard. (1993), The Logic of Anarchy: Neorealism to Structural realism. New York, CUP.

BUZAN, Barry; LITTLE, Richard. (2000), International Systems in World History: remaking the study of international relations. Oxford, OUP.

BUZAN, Barry; LITTLE, Richard. (2001), “The 'English Patient' Strikes Back: A Response to Hall's Mis-Diagnosis". International Affairs, v. 77, n. 4, p. 943-946.

CARR, Edward. (2001), Vinte Anos de Crise. Brasília, IPRI - Ed. UnB.

DUNNE, Tim. (1989), Inventing International Society: A history of the English School. London, Machmillan.

DUROSELLE, Jean-Baptiste. (2002), Todo Império Perecerá. Brasília, IPRI - Ed. UnB.

DUROSELLE, Jean-Baptiste; RENOUVIN, Pierre. (1967), Introdução à História das Relaçōes Internacionais. São Paulo, EDIPE.

HALL, Ian. (2001), "Still the English patient? Closures and Inventions in the English School". International Affairs, v. 77, n. 4, p. 931-942.

JONES, Roy. (1981), "The English school of international relations: A case for closure”. Review of International Studies, v. 7, n. 1, p. 1-13.

MORGENTHAU, Hans. (2002), A Política entre as Nações. Brasília, IPRI - Ed. UnB.

RENOUVIN, Pierre. (1994), Histoire des Relations Internationales. Paris, Hachette.

SARAIVA, José Flávio Sombra. (2006), "Revisitando a Escola Inglesa”. Revista Brasileira de Politica Internacional, ano 40, n. 1, p. 131-138.

WALTZ, Kenneth Neal. (1979), Theory of International Politics. New york, Mcgraw-Hill Book C0.

WATSON, Adam. (1992), A evolução da sociedade internacional. Brasília, IPRI - Ed. UnB.

WIGHT, Martin. (2002), A Política do Poder. Brasília, IPRI - Ed. UnB. 


\section{Resumo}

Este artigo revisita a Escola Inglesa - da obra seminal de Hedley Bull em 1977, passando pelos esforços de Adam Watsom nos anos 80, e culminando com o repaginamento de Barry Buzan e Richard Little na década de 90 - resgatando sua ontologia histórica e esboçando um programa de pesquisa que a concilie com o da historiografia francesa. Conclui-se que pode ser detectado um sistema de causalidades múltiplas em nível sistêmico, com forças profundas materiais e psicosociais operando sob os auspícios do conceito de ordem, tão crucial a esta escola.

\section{Abstract}

This paper revisits the English School from the seminal work of Hedley Bull in 1977, passing by the efforts of Adam Watsom in the 80's, and culminating with Barry Buzan and Richard Little repagination in the 90 's. It aims to rescue the school's historical ontology and sketch a research program that conciliates it with the French historiography one. One concludes that a system of multiple causalities can be detected in a systemic level, with material and psycho-social deep forces operating under the auspices of the concept of order, so crucial to this school.

Palavras-chave: Teoria das Relações Internacionais Escola Inglesa; Historiografia Francesa; Forças Profundas.

Key words: International Relations Theory; English School; French Historiography; Deep Forces. 